Original Research Article

\title{
Drug utilization pattern and analysis of quality of life in Indian patients of Parkinson's disease
}

\author{
Jugal Shah ${ }^{1}$, Pranav Joshi ${ }^{2}$, Shikha V. Sood ${ }^{3 *}$, Devang Rana ${ }^{3}$, Supriya D. Malhotra ${ }^{3}$
}

\author{
${ }^{1}$ Student, ${ }^{3}$ Department of \\ Pharmacology, Smt. NHL \\ Muncipal Medical College, \\ ${ }^{2}$ Department of Neurology, SVP \\ Hospital, Ahmedabad, Gujarat, \\ India
}

Received: 28 June 2019

Revised: 18 August 2019

Accepted: 20 August 2019

*Correspondence to:

Dr. Shikha V. Sood,

Email: shikhavsood@gmail.com

Copyright: (C) the author(s), publisher and licensee Medip Academy. This is an openaccess article distributed under the terms of the Creative Commons Attribution NonCommercial License, which permits unrestricted noncommercial use, distribution, and reproduction in any medium, provided the original work is properly cited.

\begin{abstract}
Background: Parkinson's disease (PD) is a highly debilitating disease characterized by tremors, bradykinesia and rigidity. It leads to lowered selfesteem and psychological consequences which affect quality of life. The aim of this study is to study the drug utilization pattern and assess the quality of life in patients of Parkinson's Disease.

Methods: 40 patients of PD at least 1 month duration and 20 age-based controls were analyzed for quality of life using Parkinson's Disease Questionnaire-39 (PDQ-39). Drug prescriptions were analyzed.

Results: Mean number of anti-Parkinson drugs prescribed is 2.65 \pm 1.21 . Of 106 anti-Parkinson drugs prescribed, $45 \%$ were levodopa and carbidopa combinations, followed by dopamine agonists (18\%), anticholinergic drugs $(15 \%)$, amantadine $(12 \%)$, MAO inhibitors $(5 \%)$ and COMT inhibitors $(5 \%)$. There were significant problems in speech, performance of daily chores and daytime somnolence $(\mathrm{p}<0.0001)$. Depression, isolation, cognitive decline and memory loss were noteworthy in the patients as compared to controls $(\mathrm{p}<0.05)$. $25 \%$ patients felt embarrassed due to their disease; $59 \%$ felt affected by others' opinion, $60 \%$ felt difficulty in communicating with others $(p<0.05)$. Almost $2 / 3^{\text {rd }}$ patients needed help in personal care as compared to the control group $(\mathrm{p}<0.0001)$.

Conclusions: Quality of life of parkinsonian patients is severely affected in spite of them receiving a large number of drugs. This may be both due to disease progression as well as medication. Levodopa-carbidopa combination is the most prescribed medication. Use of levodopa and carbidopa combination must be evaluated properly. Newer guidelines and interventions are the need of the hour which may provide a better outcome on the quality of life of parkinsonian patients.
\end{abstract}

Keywords: Parkinson's, Quality of life, Drug utilization

\section{INTRODUCTION}

Parkinson's disease (PD), a neurodegenerative condition is a motor system disorder due to loss of dopamineproducing brain neurons. The primary symptoms of PD are tremors in hands, arms, legs, jaw; facial rigidity, stiffness of the limbs and trunk; bradykinesia and slowness of movement; postural instability, or impaired balance and coordination.

The prevalence of the disease ranges from 41 people per 100,000 in the fourth decade of life to more than 1,900 people per 100,000 among those 80 and older. ${ }^{2}$
Multiple anti-Parkinson drugs are available for treatment, such as levodopa-carbidopa combination, COMT Inhibitors, MAO inhibitors, dopamine agonists, nondopaminergic therapy, etc. ${ }^{3}$ However, none of these can reverse or cure the condition. Monitoring the patient response helps to correlatethe therapeutic efficacy with the drug treatment and also provides feedback to theprescribers. 4

Quality of life (QOL) is a multi-dimensional construct, which consists of at least three broad domains: physical, mental and social. If Health Related Quality of Life (HRQOL) is regularly measured in such patients it will 
help to identify factors which affect the QOL and appropriately manage them. The aspects of disease which are perceived as important may be different for patients, clinicians and researchers. For example, slowness and tremors are the main focus of clinicians while patients maybe more troubled by non-motor symptoms like nocturia, urinary frequency, fatigue, drooling and forgetfulness. These may cause more distress to the patient, but may not be reported or may be overlooked. ${ }^{5}$

Therefore, evaluation of the severity of any disease should include not only the clinical factors but also the psychological and social factors pertaining to the patient. Parkinson's disease has a profound negative impact on the QOL as pointed out by studies, patients suffer from fatigue, dementia, emotional problems, sleep disorders, difficulty in speech and balance, depression, diminished cognitive functions and several other lifestyle changes. ${ }^{6}$

A relationship between prescribed drugs and QOL of patient can be established. Though, one should keep in mind that variables other than drugs, for example social support, emotional support, etc. also affect the QOL.

For analysis of QOL, some questionnaires were developed exclusively for patients with PD. One of the known scales is Parkinson's disease quality of life questionnaire (PDQL). Martinez-Martin believe that the 39-item Parkinson's Disease Questionnaire is the most thoroughly tested and applied questionnaire and is more useful than other scales in evaluating the results of rehabilitation and drug treatment of PD or neurosurgery. ${ }^{7}$

Very few studies are available in the Indian setup pertaining to the quality of life in patients of Parkinson disease. This study could provide an insight into what drugs are prescribed and how the quality of life is affected in patients of Parkinson's disease. This data may help in framing new guidelines taking into consideration the patient's perspective. Hence, the idea of doing this study stemmed from above speculations.

\section{Aims and objectives}

To study the drug utilization pattern, assess the quality of life (using PDQ-39) and to establish a correlation between both of them in patients with PD.

\section{METHODS}

This study was conducted at the Department of Neurology of Sheth Vadilal Sarabhai Hospital, which is a tertiary care teaching hospital of Ahmedabad, after the approval of Institutional Ethics Committee (IEC).This was an observational, cross sectional study conducted in a span of 8 weeks from April 2018 to July 2018. Patients who attended Out Patient Department (OPD) and/or admitted in the ward of Neurology, diagnosed with PD (minimum one month ago) were included in this study.

\section{Inclusion criteria}

Patients with age more than 18 years, patients attending OPD and/or admitted in wards, diagnosed with Parkinson's Disease, at least 1 month before and patients willing to give informed consent for the study.

\section{Exclusion criteria}

Patients not willing to give consent and those who having any psychotic disorders.

\section{Study design}

Medical case sheets, drug charts and laboratory investigations of the consented patients were recorded in self-designed standardized Performa. Demographics (age, gender), chief complaints, provisional diagnosis, medical history, medication prescribed (dose, route of administration, frequency, indication, therapy duration, marketing categories [generic/branded]) were collected in the Case Record Form.

\section{QOL questionnaire}

Additionally, every patient was supplemented with a Parkinson Disease Questionnaire - 39(PDQ-39) in their vernacular language, for which the permission was taken from concerned authority and was filled under the guidance of student, coordinating with the patient's relative.

The same questionnaire was also filled up by 20 agematch controls, to assess the differences in the QOL of both the groups.

Table 1: Segregation of questions into domain.

\begin{tabular}{|ll|}
\hline Domain & Question number \\
\hline Physical & $1,3,4,5,7,14,16,30,34,37,38,39$ \\
\hline Psychological & $9,17,18,19,20,21,22,24,31,32$, \\
\hline Social & $27,28,29,35$ \\
\hline $\begin{array}{l}\text { Level of } \\
\text { Independence }\end{array}$ & $2,6,8,10,11,12,13,15$ \\
\hline Environment & 23 \\
\hline $\begin{array}{l}\text { Personal } \\
\text { Beliefs }\end{array}$ & $25,26,36$ \\
\hline
\end{tabular}

PDQ-39 contains 39 questions spanning across various dimensions of life. According to the World Health Organization, QOL consists of six significant domains: physical, psychological, level of independence, social relationships, environment, and spirituality, religion or personal beliefs. ${ }^{8}$ The 39 questions were sorted into 6 domains as shown in Table 1.

Each question asked the patient how often she/he has experienced a certain event due to PD. Ratings are made 
on a five-point Likert scale from 1 "Always" to 5 "Never." The range for each answer being depending upon the number of questions in each domain, the maximum, minimum and total score of each domain is shown in Table 2.

Total score is calculated by adding the individual scores of all 5 domains. Score ranges from 39 - 195. It is divided into 5 categories, thereby grading the Level of Impairment of QOL. Higher the score better is the Q0L. Lower the score the more impaired is QOL (Table 3).
Table 2: Using the Likert scale to rate answer.

\begin{tabular}{|c|c|c|}
\hline \multicolumn{3}{|c|}{ Likert scale } \\
\hline 5 & Never & Positive \\
\hline 4 & Occasionally & \\
\hline 3 & Sometimes & \\
\hline 2 & Often & 5 \\
\hline 1 & Always & Negative \\
\hline
\end{tabular}

Table 3: Calculation of individual domain score.

\begin{tabular}{|lllll|}
\hline Domain & Number of questions & Maximum score & Minimum score & Range \\
\hline Physical & 12 & 60 & 12 & $12-60$ \\
\hline Psychological & 11 & 55 & 11 & $11-55$ \\
\hline Social & 4 & 20 & 4 & $4-20$ \\
\hline Level of independence & 8 & 40 & 8 & $8-40$ \\
\hline Environment & 1 & 5 & 1 & $1-5$ \\
\hline Personal Beliefs & 3 & 15 & 3 & $3-15$ \\
\hline
\end{tabular}

\section{Statistical analysis}

Data obtained from all such Case Record Form and PDQ39 was entered into Microsoft Excel, 2016 version. Analysis was carried out using Pearson Correlation Coefficient Test between Quality of life and drug therapy. $\mathrm{P}<0.05$ was considered statistically significant. All the statistical analysis was done by using SPSS (Statistical Package for Sciences) version 23.0 (IBM corporation California).

\section{RESULTS}

Data collection of 40 patients and 20 age-matched controls (patient's relative) was undertaken for 2 months.
In the end, data analysis was carried out and the results obtained were discussed further in this section.

\section{Age and gender distribution}

Mean age of Patient population was $61.88 \pm 11.932$ years, with maximum patients $(35 \%)$ belonging to age group 61-70years (Figure 1). Age-matched Control population has been taken, with a mean age of $61.45 \pm 16.330$ years. Out of 40 patients, prevalence of Parkinson's disease among males is 27 while that in females is 13. Male to female ratio is 2.077 indicating preponderance among males.

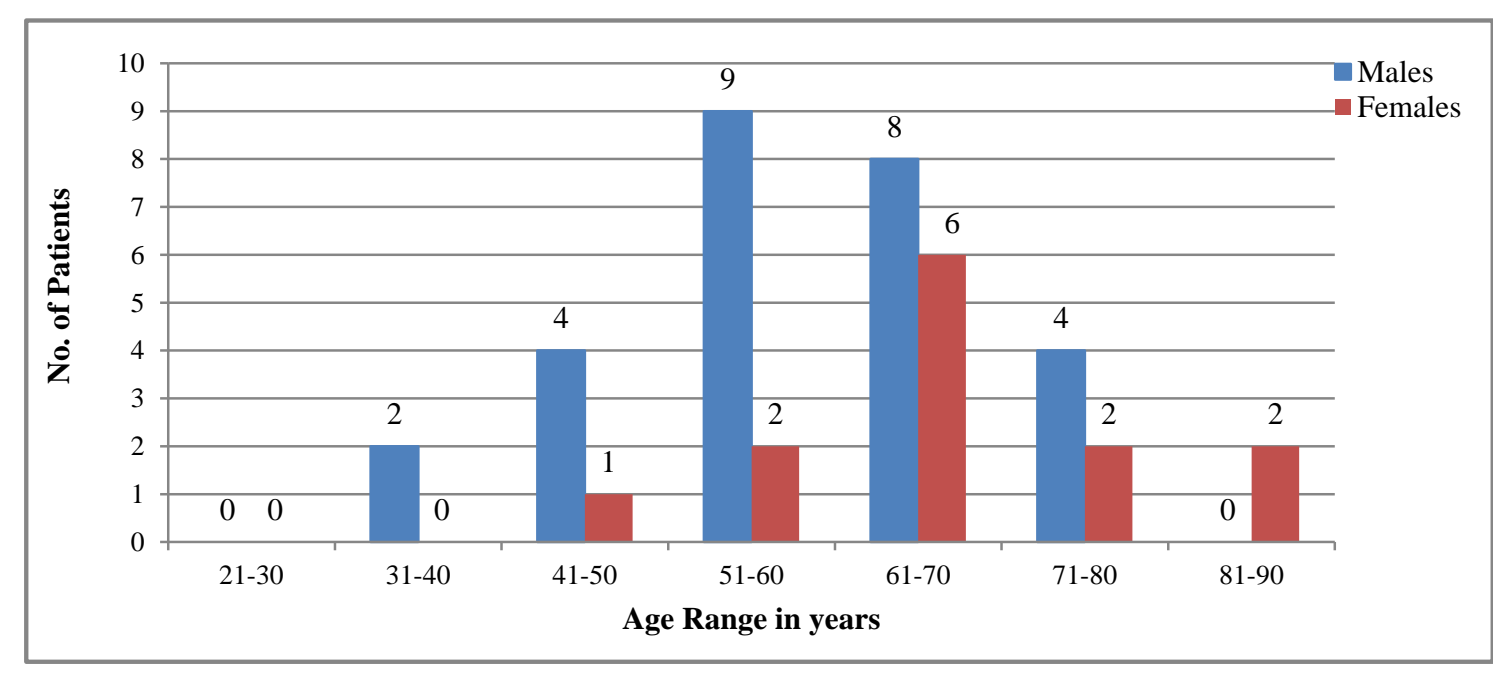

Figure 1: Age and gender distribution of patients. 


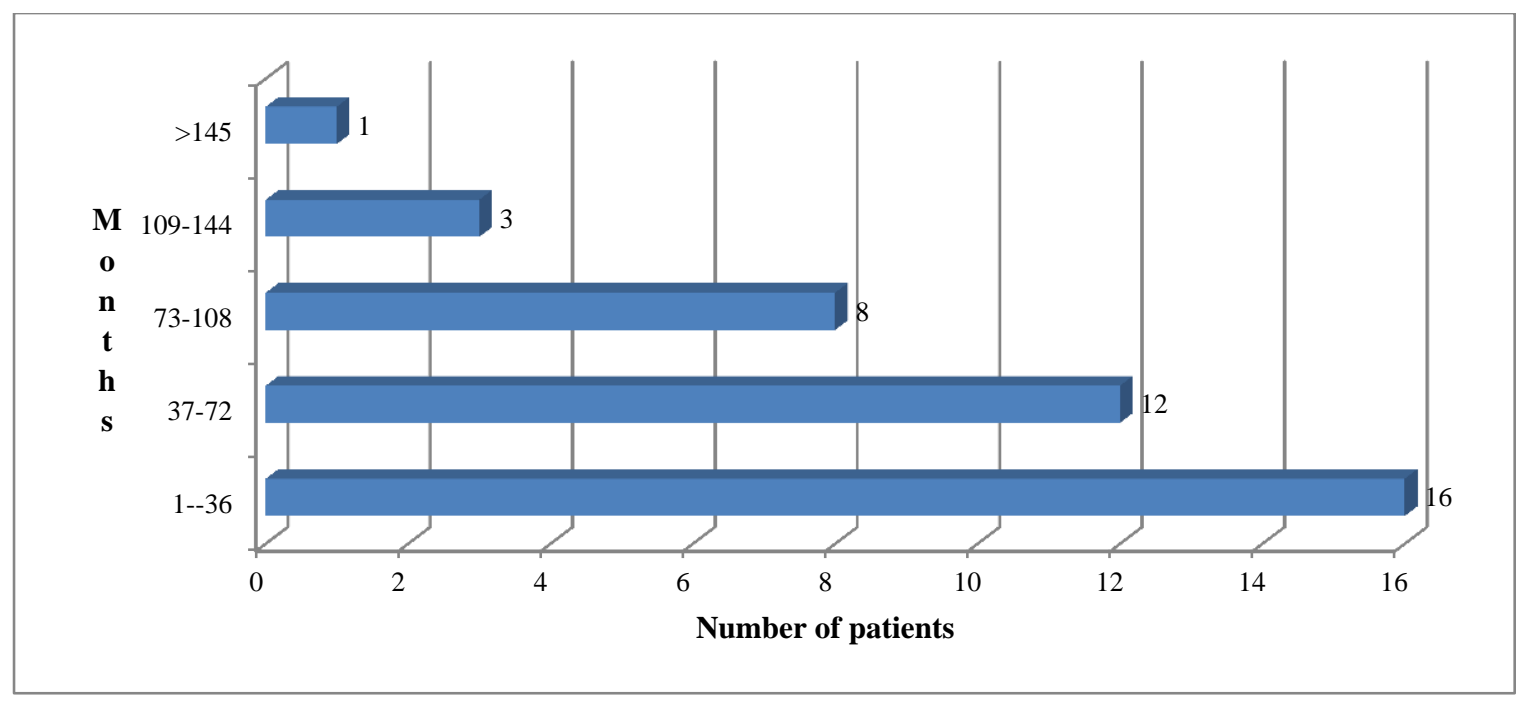

Figure 2: Duration of illness in patients of PD.

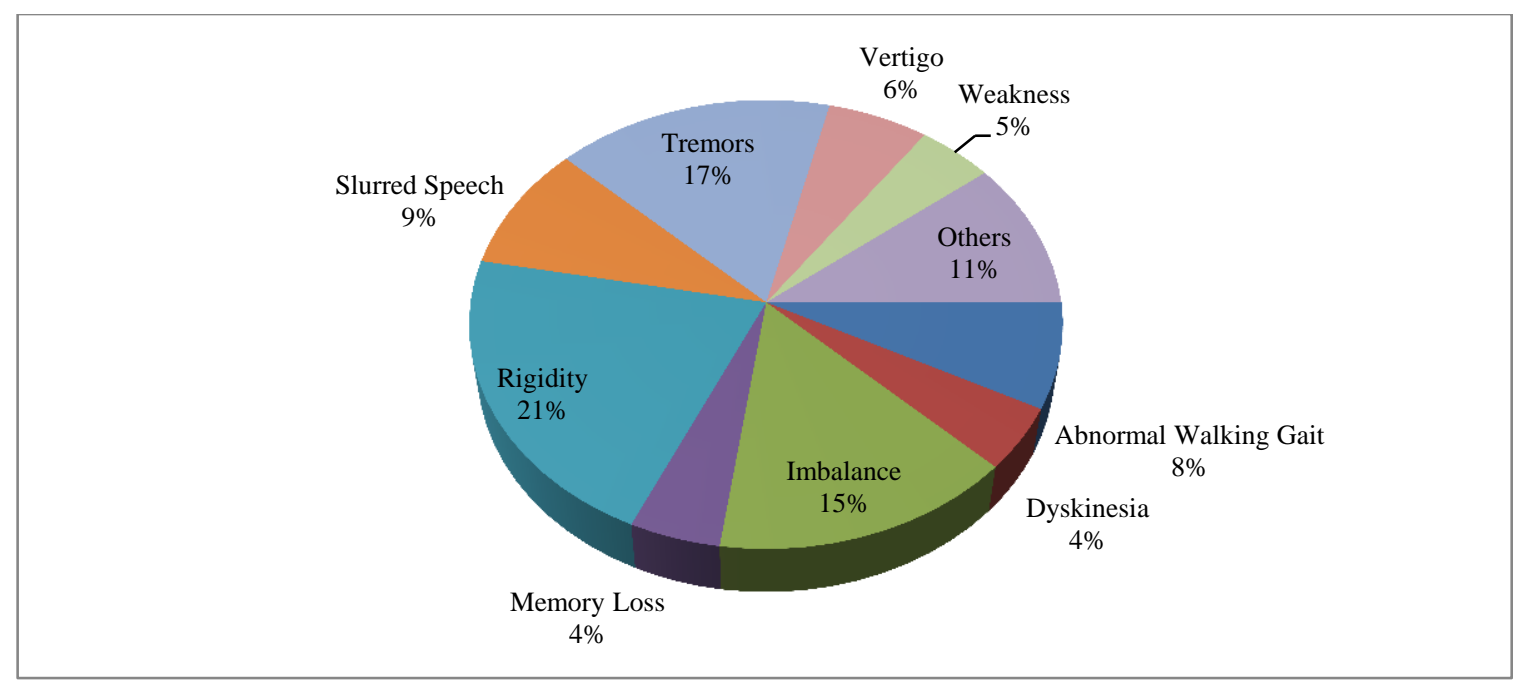

Figure 3: Chief complaints of patients in PD.

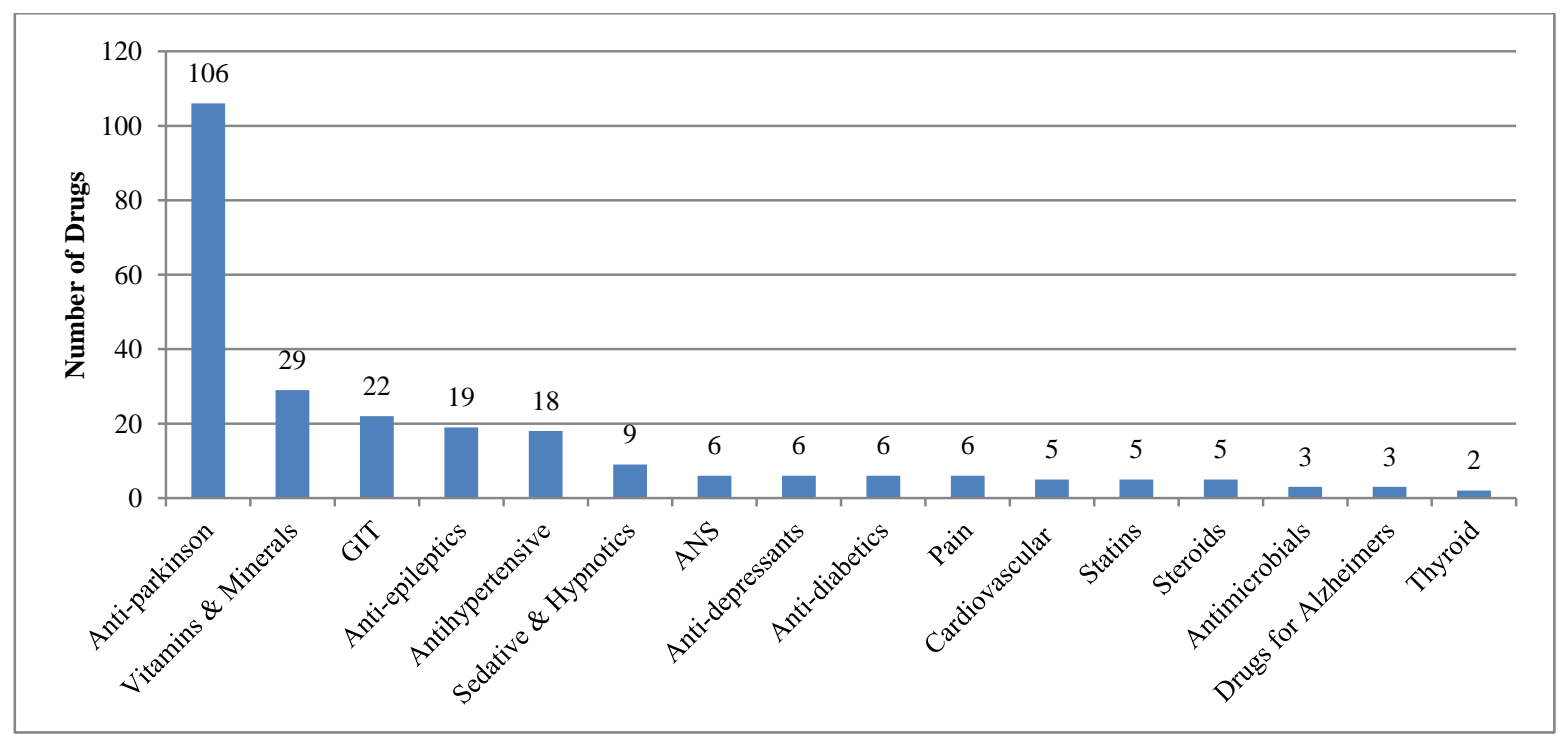

Figure 4: Drug utilization pattern. 


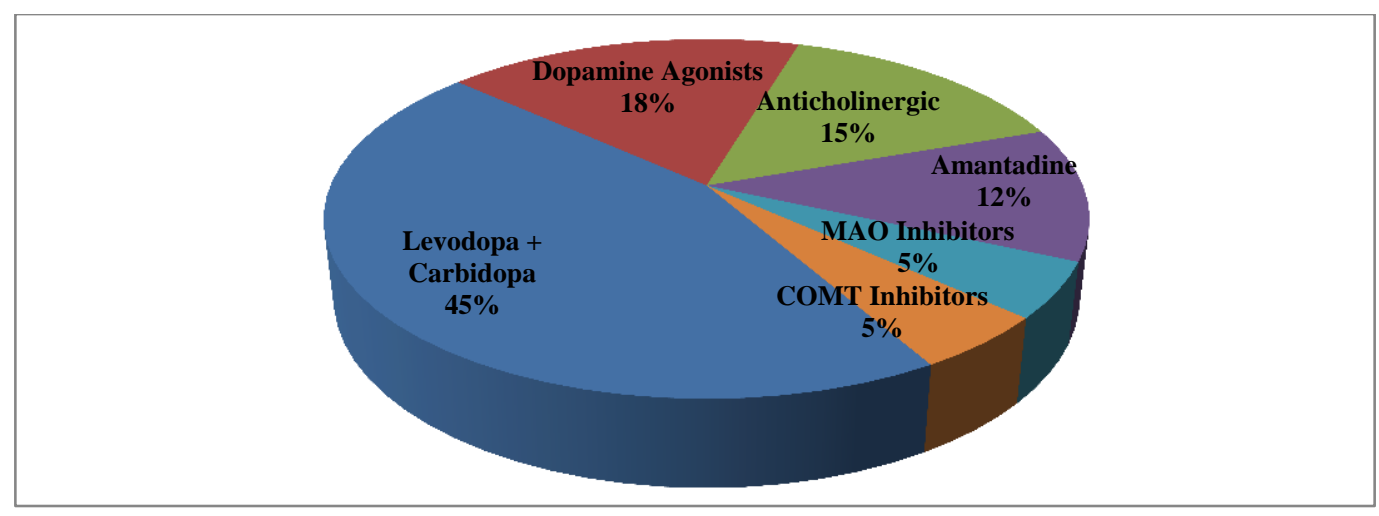

Figure 5: Drug utilization pattern of anti-Parkinson drugs.

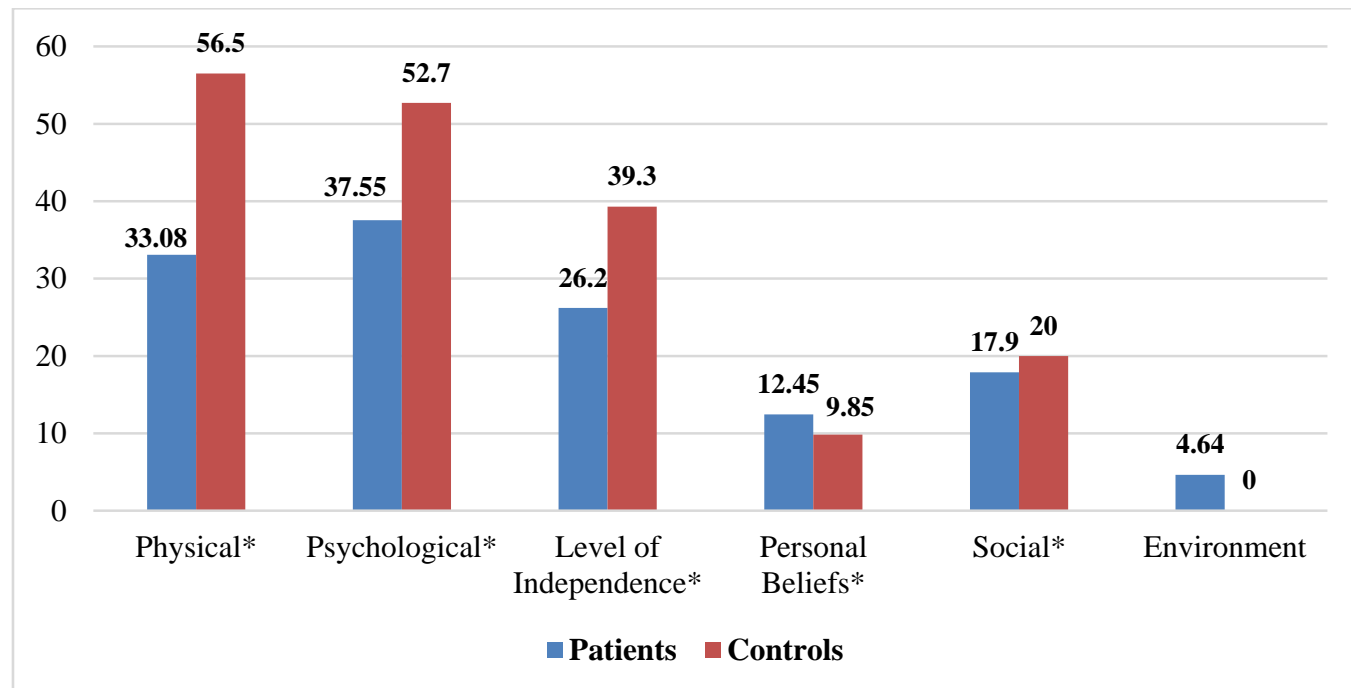

Figure 6: Comparison of individual domain score of patients suffering from PD (*means $\mathbf{p}<0.05$, extremely significant).

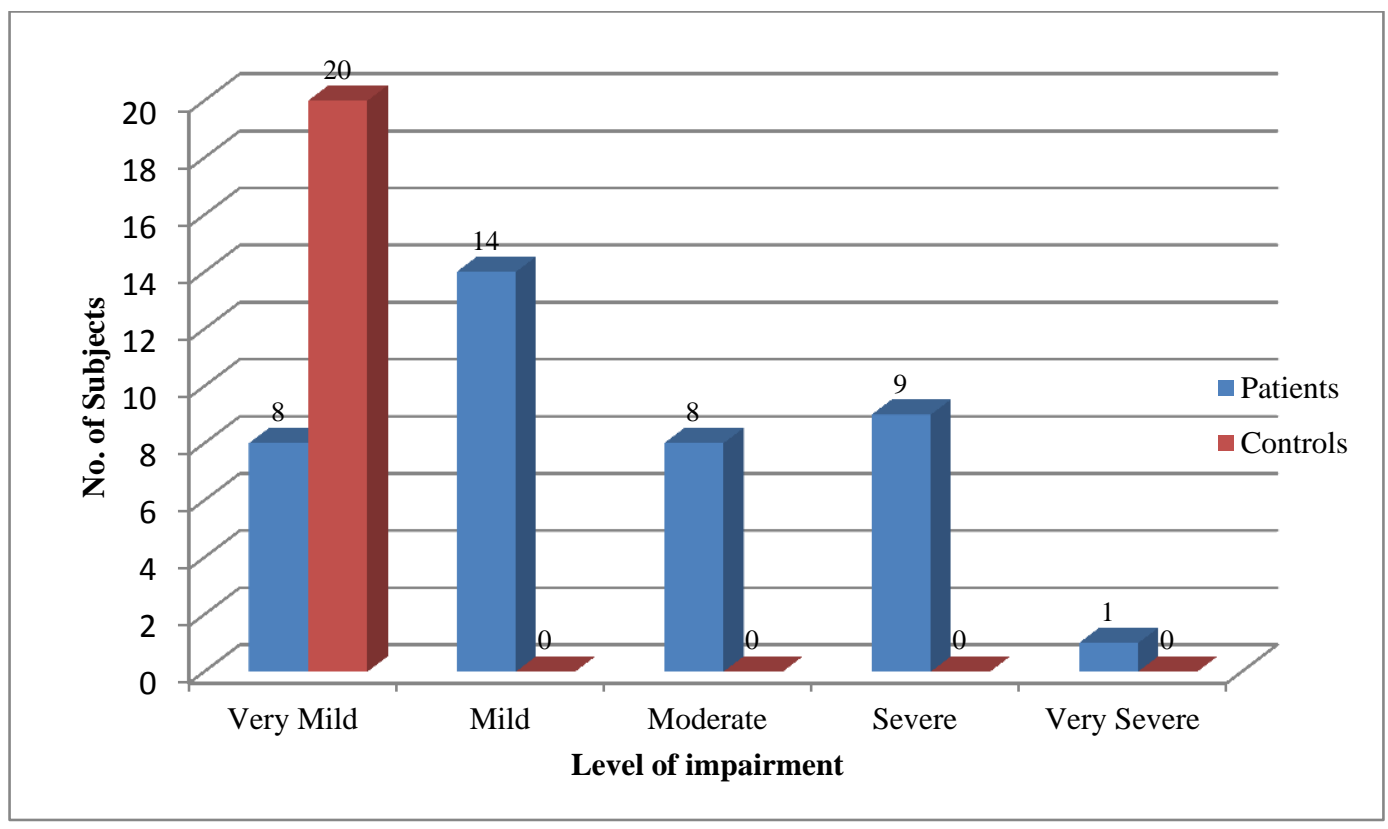

Figure 7: Comparison of total QOL score in patients of PD with controls. 


\section{Duration of illness}

Mean duration of illness observed in patients suffering from Parkinson's disease is $59.125 \pm 40.978$ months (Figure 2). PD had set in around 1-36 months ago in about $40 \%$ of patients. $30 \%$ patients had a history of PD from past 37-72 months.

\section{Chief complaints}

On questioning about what problems the patient faced in their day-to-day lives, 66 complaints were received (Figure 3). The chief complaints were Rigidity (14), Tremors (11), Imbalance (10), Slurred Speech (6), Abnormal Walking Gait (5), Vertigo (4), Weakness (3), Dyskinesia (3), Memory Loss (3), Nausea (2), Dirty Man Syndrome (1), Abdominal Pain (1), Sleeplessness (1), Vomiting (1), Paralysis (1).

\section{Drug utilization pattern}

Over 250 drugs including both drugs for PD and other comorbid conditions were prescribed to the 40 patients in a span of 8 weeks. Mean number of drugs received by each patient is $6.25 \pm 2.097$. These 250 drugs were classified in 16 different pharmacological drug groups (Figure 4).

Table 4: Grading of level of impairment based on total QOL score.

\begin{tabular}{|ll|}
\hline Level of impairment of QOL & Total score \\
\hline Very Mild & $163-195$ \\
\hline Mild & $132-162$ \\
\hline Moderate & $101-131$ \\
\hline Severe & $70-100$ \\
\hline Very Severe & $39-69$ \\
\hline
\end{tabular}

Table 5: Prescription frequency of anti-Parkinson drugs $(n=40)$.

\begin{tabular}{|lll|}
\hline $\begin{array}{l}\text { Name of drug } \\
\begin{array}{l}\text { Levodopa + Carbidopa } \\
\text { (125mg) }\end{array}\end{array}$ & 38 & $\%$ \\
\hline Ropinirole & 14 & 95 \\
\hline Trihexyphenidyl & 13 & 35 \\
\hline Amantadine & 13 & 32.5 \\
\hline $\begin{array}{l}\text { Levodopa + Carbidopa } \\
\text { (250mg) }\end{array}$ & 9 & 32.5 \\
\hline Rasagiline & 5 & 22.5 \\
\hline Entacapone & 5 & 12.5 \\
\hline Pramipexole & 4 & 12.5 \\
\hline Rivastigmine & 3 & 10 \\
\hline $\begin{array}{l}\text { Levodopa + Carbidopa + } \\
\text { Entacapone }\end{array}$ & 1 & 7.5 \\
\hline Bromocriptine & 1 & 2.5 \\
\hline
\end{tabular}

The mean number of anti-Parkinson drug prescribed is $2.65 \pm 1.21$.
Out of 250 drugs which were analyzed in 40 prescriptions, the frequency of anti-Parkinson drugs was calculated, and is shown in the Table 4. Levodopa + Carbidopa (125mg) is the most frequently prescribed drug with its presence in $95 \%$ of prescriptions.

Based on the specific anti-Parkinson drug classes, the utilization pattern is as shown in Figure 5.

\section{Comparison of domains}

The difference between the individual domain scores of patient and control groups are shown in Figure 6. The individual scores of physical, psychological, level of independence and social domains of the control group are higher than the patient group. Since questions of personal belief and environment domain questioned directly about parkinson's disease, those were not to be filled by control groups, hence the individual scores of that domain are lower in Control group.

\section{Comparison of total QOL score}

Total QOL Score is calculated by adding all individual domain scores. It lies in the range of 39-195. Mean Total QOL Score in patient group is $130.45 \pm 34.622$, while that of Control group is $178.35 \pm 6.072$, which is extremely significant $(\mathrm{p}<0.0001)$. Higher the score, better is the QOL.

\section{DISCUSSION}

In our literature search, very few drug utilization studies for anti-Parkinson drugs and even fewer studies about the Quality of Life of patients of Parkinson's disease were found in the Indian setup, which prompted us to take up this study.

Management of PD is life-long and requires thorough patience. During multiple visits to OPD and wards, it was noticed that patient knowledge and awareness about the disease was very poor. As a result, patient compliance and follow-up were affected. Also, occurrence of side effects or adverse drug reaction was hardly acknowledged.

This observational, cross-sectional study was carried out at the Department of Neurology of a tertiary care teaching hospital. A total of 40 patients and 20 age-matched controls were included in the study, after taking their informed consent. This study was carried out in a span of eight weeks.

This study analysed the Drug Utilization Pattern of antiParkinson drugs and evaluated the quality of life of patients using Parkinson's Disease Questionnaire - 39 (PDQ-39). Any correlation between the prescribed drugs and the quality of life was also analysed. 
An analysis like this helps in improving the therapeutic efficacy, decrease the adverse effects and provide feedback to the prescribers about the standard of QOL of their patients. It will help to improve the level of medical care and treatment in the Indian Healthcare System.

The mean age group of presenting patients is $61.45 \pm 16.330$ years. Majority of patients were above 50 years of age; 7 patients were suffering from young onset PD (onset between 35-50 years). The youngest patient aged 37, while the eldest aged 87 . Mean duration of illness is $59.125 \pm 40.98$ months $(4.93 \pm 3.415$ years $)$.

Our study showed preponderance among males, with observed male to female ratio is 2.077:1. Multiple studies have indicated that male to female ratios for incidence rates vary from 1.37 to $3.7 .^{10}$

In our study, the chief motor complaints were Rigidity (21\%), Tremors (17\%), Imbalance (15\%), Slurred Speech (9\%), Abnormal Walking Gait (8\%), Vertigo (6\%), Dyskinesia (4\%) and Paralysis (1.5\%). While chief nonmotor complaints were Weakness (5\%), Memory Loss (4\%), Nausea (3\%), Dirty Man Syndrome (1.5\%), Abdominal Pain (1.5\%), Sleeplessness (1.5\%) and Vomiting (1.5\%).

\section{Drug utilization pattern}

In our study, 250 drugs were prescribed to the 40 patients in a span of 8 weeks. Mean number of drugs received by each patient is $6.25 \pm 2.097$. Along with the anti-Parkinson drugs $(42 \%)$, patients were also being prescribed cardiovascular drugs [antihypertensives (7\%), statins (2\%), anti-platelets (2\%)], vitamins \& minerals (12\%), git drugs (9\%), anti-epileptics (8\%), sedative-hypnotics (4\%), anti-depressants (2\%), anti-diabetics (2\%), ANS drugs $(2 \%)$, steroids $(2 \%)$, pain $(2 \%)$, antimicrobials $(1 \%)$, drugs for hypothyroidism $(1 \%)$ and drugs for Alzheimer's (1\%).

It was observed that almost fifty percent of patients were being prescribed cardiovascular drugs in the form of antihypertensive, anti-platelets, drugs for IHD and statins. The patients were also being prescribed drugs for neurological disorders like epilepsy, Alzheimer's, antidepressants and sedatives-hypnotics. Majority of patients were supplemented with multivitamin, folic acid and calcium tablets as most of them belonged to lower socioeconomic categories.

In our hospital setup, the mean number of anti-Parkinson drug prescribed is $2.65 \pm 1.21$. The prescribing frequency of levodopaand and carbidopa (125 mg) combinationis $95 \%$, followed by ropinirole (35\%), trihexyphenidyl $(32.5 \%)$, amantadine (32.5\%), levodopa and carbidopa $(250 \mathrm{mg})$ in $22.5 \%$, rasagiline $(12.5 \%)$, entacapone $(12.5 \%)$, pramipexole (10\%), rivastigmine $(7.5 \%)$, combination of levodopa, carbidopa, entacapone (2.5\%) and bromocriptine $(2.5 \%)$.
In our study, levodopa and carbidopa are the most prescribed drug, present in every single prescription that was analyzed. Even though Levodopa is associated with troublesome dyskinesias, on/off effect, dirty man syndrome, etc, yet it is the first choice due to its efficacy, ease of accessibility and economy.

Prescription guidelines by American Academy of Family Physicians suggest thatas soon as functional impairment sets in, patient should be prescribed with levodopa/carbidopa or a dopmaine agonist. Our study was in agreement with these guidelines, since levodopa/carbidopa was prescribed to every single patient in one or other formulations. however, prescribing frequency of dopamine agonist was around $48 \%$ of total prescriptions. ${ }^{11}$

National Institute for Health and Care Excellence(NICE) guidelines of United Kingdom suggests that patient should be offered a choice among Levodopa, Dopamine Agonist and MAO-B inhibitors for early motor symptom treatment, if it doesn't affect their QOL. If QOL is affected, treatment must be initiated with Levodopa only. Our study was found correlating to these guidelines. ${ }^{12}$

Results observed in a study carried out in Karnataka, show that Levodopa was prescribed in $94.8 \%$, Trihexyphenidyl in $40.4 \%$, dopamine agonists in $23.2 \%$, and Amantadine in $17.2 \%$ either as monotherapy or in combination. $^{13}$

In our study, out of 106 anti-Parkinson drugs prescribed, $45 \%$ were Levodopa and Carbidopa combinations, followed by dopamine agonists (18\%), anticholinergic drugs (15\%), amantadine (12\%), MAO inhibitors (5\%) and COMT inhibitors $(5 \%)$.

PD generally follows a progressive course. The benefits of Levodopa often diminish with time, and serious adverse effects may complicate long-term Levodopa treatment. Levodopasparing interventions (e.g., dopamine agonist monotherapy or rasagiline in early PD), may be able to delay motor complications, whereas the initiation of Levodopa might be withheld until the patient needs additional symptomatic benefit or if side effects limit the use of other agents. The symptomatic treatment of mild PD is probably best avoided until a disability or symptoms begin to affect the patient's lifestyle. Hence, the rampant use of levodopa and carbidopa combination must be evaluated properly. ${ }^{14}$

For the individual patient, rational use means prescription of a well-researched drug at an optimal dose, treating his condition promptly and with minimum side effects, that too at an affordable price.

\section{Quality of life}

In our study, we evaluated the QOL in patients with Parkinson's disease with respect to physical, social, 
psychological, level of independence, personal beliefs and environment domains. Each domain was analyzed separately using a wide spectrum of questions.

Based on the total score of domains, the QOL of patients and controls was categorized into very mild, mild, moderate, severe and very severe level of impairment. The proportion of patients with moderate to very severe levels of impairment was $45 \%$, while all age-matched controls had very mild level of impairment.

\section{Physical domain}

On analysis of individual domains, it was observed that there was statistically significant difference in the Physical Domain in patients as compared to controls. The mean score of physical domain in patients is $33.08 \pm 11.40$ and in controls is $52.7 \pm 2.56$, which is extremely significant $(\mathrm{p}<0.0001)$. Patients had difficulty in doing their favourite activities, carrying bags, getting around in public, difficulty holding a glass $(\mathrm{p}<0.05)$.

Patients also had muscle cramps and sometimes felt unpleasantly hot/cold, compared to the controls $(\mathrm{p}<0.05)$. Patients complained of joint/body ache, since the Agematched controls also faced similar joint/body ache the result was insignificant ( $\mathrm{p}>0.05)$.

A significant observation among patients is difficulty in walking $(p<0.05) .60 \%$ of patients had problem in walking the initial 100 meters. The Chief complaints reported among patients included Abnormal Walking Gait, Imbalance, Tremors as well as Rigidity, which shows why walking is severely affected, which affects the Total QOL directly.

Freezing of Gait was the strongest significant contributing factor to perceived walking difficulties, followed by general self-efficacy, fatigue, PD duration, lower extremity function, orthostatic hypotension, bradykinesia and postural instability. ${ }^{15}$

Patients faced problem in writing due to trembling of hands, and could not write properly $(\mathrm{p}<0.05)$. Unexpected sleep during the day is increased $(\mathrm{p}<0.05)$. PD affects speech and impairs the quality of speech and communication $(\mathrm{p}<0.05)$.

\section{Psychological domain}

The mean score of Psychological Domain in patients is $37.55 \pm 15.67$ and in controls is $52.7 \pm 2.56$, which is extremely significant $(\mathrm{p}<0.0001)$. On the emotional front, the patients often felt depressed, isolated or lonely, weepy or tearful, angry or bitter, anxious and even worried about their future $(p<0.05)$. While cognitive impairment like concentration issues, memory loss, distressing dreams and hallucinations are also observed $(\mathrm{p}<0.05)$. Patients avoided eating in public and even feared falling down $(\mathrm{p}<0.05)$.

\section{Social domain}

The mean score of social domain in patients is $17.9 \pm 2.658$ and in controls is $20 \pm 0.00$, which is extremely significant $(\mathrm{p}<0.0009)$. It was observed in the social domain that patients did not face problems with close relationships, or did not lack support from spouse/partner or family/close friends due to the disease (not significant, $\mathrm{p}>0.05$ ). This could be due to strong Indian cultural system and family values. The patients often felt that they are unable to communicate properly due to the disease $(\mathrm{p}<0.05)$.

A similar result was also observed in a study carried out at Kolkata in 2006, which also showed that family and community relationships were minimally altered due to good bondage among Indian families. ${ }^{16}$

\section{Level of independence}

The mean score of Level of Independence in patients is $26.20 \pm 9.775$ and in controls is $39.30 \pm 1.129$, which is extremely significant $(\mathrm{p}<0.0001)$. Patients faced problems in doing household chores or even in getting around the house, washing and dressing themselves, tying shoe laces and even in cutting up food (significant, $\mathrm{p}<0.005)$. A significant increase in time spent in house was also observed among the patients, due to disease disability.

The symptoms of PD - tremor, stiffness, slow movement and balance problems-worsen over time, and can make it more difficult to do things like getting in and out of a bathtub, standing up from a chair, or walking. ${ }^{17}$

\section{Environment}

Though significant, majority of the patients (85\%) responded that they never had to conceal the disease from other people. A plausible explanation is that tremors, rigidity, etc. which are the cardinal signs of Parkinson's disease, are easily visible; hence, it is difficult to hide the disease.

\section{Personal beliefs}

$75 \%$ of patients did not feel embarrassed in public due to their disease. Though people's reaction did matter to some, the feeling of being ignored by others is also observed $(p<0.05)$. Stigma is not only a feeling of shame and embarrassment arising from a self-perception of inadequacy due to loss of autonomy and visible symptoms but also an experience related to the attitudes and beliefs of the social context towards the PD patient who is stigmatized and forced to withdrawal. ${ }^{18}$ 


\section{Strengths of the study}

This study is first of its kind in patients suffering from Parkinson's disease and was carried out at a tertiary care teaching hospital. This study does not only analyze the drug utilization pattern in the treatment of Parkinson's disease, but also assessed the impact on physical, psychological, level of independence, social, environmental and personal beliefs domain using a robust QOL questionnaire, that is, PDQ-39. This study also analysed in-depth about each domain between the patients and controls and found that walking, speech and communication, anxiety, depression were the most affected aspects of patients suffering from Parkinson's disease.

\section{Limitations of the study}

This study was a duration based study, so a limited sample size of 40 patients was collected. Hence, entire spectrum of the disease and QOL correlation will not be robust. As it was a prospective, single point study, the alterations in the QOL of the patients could not be assessed. Because of time constraint we could not use other Parkinson's tool and correlate them.

\section{CONCLUSION}

The drug utilization pattern indicated that Levodopa + Carbidopa $(125 \mathrm{mg})$ formed the major part of the treatment plans as compared to other drugs. Our study has also described the impact of Parkinson's disease on Quality of Life. To conclude it was observed that QOL was significantly affected in physical, psychological, social, level of independence, environment and personal belief domains in spite of patients receiving so many drugs for their disease. Drug therapy of mild symptomatic PD is probably best avoided until the symptoms begin to affect the patient's lifestyle. Hence, the rampant use of levodopa and carbidopa combination must be evaluated properly. Newer guidelines and interventions are the need of the hour to have a better outcome on the quality of life of parkinsonian patients.

\section{ACKNOWLEDGEMENTS}

This research was supported by the Indian Council of Medical Research (ICMR), with support of our Dean and the Superintendent, along with the Deparment of Neurology who allowed us to conduct the research in the hospital premises. I also extend my gratitude to the Deparment of Pharmacology who provided insight and expertise that greatly assisted the research.

\section{Funding: No funding sources} Conflict of interest: None declared

Ethical approval: The study was approved by the Institutional Ethics Committee

\section{REFERENCES}

1. National Institute of Neurological Disorders and Stroke.Parkinson's Disease Information Page, 2019. Available at: https://www.ninds.nih.gov/Disorders/ All-Disorders/Parkinsons-Disease-Information-Page. Accessed 13 August 2019.

2. Parkinson's News Today, 2012. Available at: https://parkinsonsnewstoday.com/parkinsons-diseasestatistics/. Accessed 13 August 2019.

3. Djokovic J, Aguilar LG. Current approaches to the treatment of Parkinson's disease. Neuropsychiatric Disease and Treatment by Dove Medical Press. 2008;4(4):743-57.

4. Dukes MNG. Development from Crooks to the nineties. In: Auditing Drug Therapy. Approaches towards rationality at reasonable costs. Stockholm: Swedish Pharmaceutical Press; 1992.

5. Reichmann H, Stocchi F, Martin P. Quality of life in parkinson's disease-patient, clinical and research perspectives. European Neurological Review. 2014;9(12):7-12.

6. Opara J. Current possibilities of evaluation of quality of life in Parkinson disease. Neurol Neurochir Pol. 2003;37(Suppl 5):241-50.

7. Martinez-Martin P, Jeukens-Visser M, Lyons KE, Rodriguez-Blazquez C, Selai C, Siderowf A, et al. Health-related quality-of-life scales in Parkinson's disease: critique and recommendations. Mov Disord. 2011;26(13):2371-80.

8. The WHOQOL Group: The World Health Organization Quality of Life assessment (WHOQOL): position paper from the World Health Organization. Soc Sci Med. 1995,41:1403-9.

9. Likert R. A Technique for the Measurement of Attitudes. Archives of Psychology. 1932;140:1-55.

10. Gillies GE, Pienaar IS, Vohra S, Qamhawi Z. Sex differences in Parkinson'sdisease. Front Neuroendocrinol. 2014;35(3):370-84.

11. Rao S, Hofmann L, Shakil A. Parkinson's Disease: Diagnosis and Treatment. Am Fam Physician. 2006;74(12):2046-54.

12. National Institute for Health and Care Excellence. Parkinson's disease in adults: diagnosis and management, 2017. Available at: https://www.nice. org.uk/guidance/ng71/documents/short-version-ofdraft-guideline. Accessed 6 June 2019.

13. Surathi P, Kamble N, Bhalsing K, Yadav R, Pal P. Prescribing Pattern for Parkinson's Disease in Indian Community before Referral to Tertiary Center. Canadian J Neurol Sci. 2017;44(6):705-10.

14. Goldenberg MM. Medical Management of Parkinson's Disease. Pharmacy and Therapeutics. 2008;33(10):590-606.

15. Kader M, Ullén S, Iwarsson S, Odin P, Nilsson MH. Factors Contributing toPerceived Walking Difficulties in People with Parkinson's Disease. J Parkinsons Dis. 2017;7(2):397-407. 
16. Ray J, Das SK, Gangopadhya PK, Roy T. Quality of life in Parkinson'sdisease--Indian scenario. J Assoc Physicians India. 2006;54:17-21.

17. National Parkinson Foundation.Activities of Daily Living: Practical Pointers for Parkinson's Disease. National Parkinson Foundation, 2018. Available at: https://www.parkinson.org/sites/default/files/Practica 1_Pointers.pdf. Accessed 13 August 2019.

18. Maffoni M, Giardini A, Pierobon A, Ferrazzoli D, Frazzitta G. "Stigma Experienced by Parkinson's
Disease Patients: A Descriptive Review of Qualitative Studies," Parkinson's Disease. 2017;ID7203259:7.

Cite this article as: Shah J, Joshi P, Sood SV, Rana D, Malhotra SD. Drug utilization pattern and analysis of quality of life in Indian patients of Parkinson's disease. Int J Basic Clin Pharmacol 2019;8:2092-101. 